\title{
PAULO FREIRE E A EDUCAÇÃO DE JOVENS E ADULTOS
}

\author{
Adenilson Souza Cunha Júnior ${ }^{1}$ \\ Sônia Maria Alves de Oliveira Reis ${ }^{2}$ \\ Tatyanne Gomes Marques ${ }^{3}$
}

Com grande alegria, apresentamos o dossiê "Paulo Freire e a Educação de Jovens e Adultos", no ano do centenário de seu nascimento. Iniciamos esta apresentação marcados(as) pela interrogação de Gadotti (2001, p. 52) “o que um educador pode deixar como legado?”. Em seguida, ele responde: Em primeiro lugar, pode deixar uma vida, uma biografia. E Paulo nos encantou, em vida, com sua ternura, doçura, carisma e coerência, compromisso e seriedade. Suas palavras e ações foram de luta por um mundo "menos feio, malvado e desumano". Ao lado do amor e da esperança, ele também nos deixa um legado de indignação diante da injustiça (GADOTTI, 2001). Para Freire (1987), o amor é uma exigência existencial que requer de nós a coragem, a humildade, o sonho de construção de um mundo melhor, a esperança para nos lançarmos em ações que implicam nossa vocação - a humanização!

No contexto das celebrações do centenário de nascimento de Paulo Freire, o teórico, filósofo da educação e educador brasileiro mais estudado, citado e homenageado no mundo, e, desde 2012, declarado Patrono da educação brasileira, a Revista Educação e Ciências Sociais (RECS) tem a honra de apresentar a seus leitores e leitoras, por meio do volume 5 e número 7, um dossiê que tem como objetivo discutir acerca da Educação de Jovens e Adultos e as contribuições de Paulo Freire para o campo da EJA em contextos escolares e não escolares.

\footnotetext{
${ }^{1}$ Doutor em Educação pela FAE/UFMG. Professor Adjunto do Departamento de Ciências Humanas, Educação e Linguagem e do Programa de Pós-Graduação em Educação da Universidade Estadual do Sudoeste da Bahia (UESB). Pesquisador do Grupo de Estudos e Pesquisas em Educação de Jovens e Adultos (GRUPEJA-UFMG). ORCID: https://orcid.org/0000-0003-3622-1799. Lattes: http://lattes.cnpq.br/2046813448859972 E-mail: adenilsoncunha@uesb.edu.br.

${ }^{2}$ Doutora em Educação pela FAE/UFMG. Professora no Departamento de Educação (DEDC XII) da Universidade do Estado da Bahia (Uneb), Guanambi-Bahia, Brasil. Líder do Núcleo de Estudo, Pesquisa e Extensão Educacional Paulo Freire (NEPE/Uneb), pesquisadora da linha de pesquisa em Educação do Campo, Educação de Jovens e Adultos e Movimentos Sociais. Professora do Programa de Pós-Graduação em Educação (PPGED/UESB). Lattes: http://lattes.cnpq.br/9391155498685665. ORCID: https://orcid.org/0000-0003-0129-0719. E-mail: smaoliveira@uneb.br

${ }^{3}$ Doutora em Educação pela FAE/UFMG. Professora no Departamento de Educação (DEDC XII) da Universidade do Estado da Bahia (Uneb), Guanambi-Bahia, Brasil. Pesquisadora vinculada ao Núcleo de Estudo, Pesquisa e Extensão Educacional Paulo Freire (NEPE/Uneb) onde coordena a linha de pesquisa em Educação do Campo, Educação de Jovens e Adultos e Movimentos Sociais. Professora do Programa de Pós-Graduação em Educação (PPGED/UESB). Lattes: http://lattes.cnpq.br/6540344146598584. ORCID: https://orcid.org/0000-00033076-3220. E-mail: tmarques@uneb.br
} 
No Brasil, pensar em Educação de Jovens e Adultos é pensar em Paulo Freire. O mais célebre educador brasileiro, com atuação e reconhecimento internacionais, conhecido principalmente pelo método de alfabetização de adultos que leva seu nome, desenvolveu um pensamento pedagógico assumidamente político. Para ele, o objetivo maior da educação é conscientizar homens e mulheres, principalmente em relação às parcelas da população desfavorecidas. A educação freiriana ${ }^{4}$ está voltada para a conscientização do analfabetismo político para concomitantemente ler o seu mundo a partir de sua experiência, de sua cultura, de sua história.

Freire mostra que se faz necessária uma educação como prática da liberdade, já que quanto mais se problematizam os/as educandos/as como seres no mundo, mais se sentirão desafiados/as e responderão de forma positiva. Ao contrário de uma educação bancária, domesticadora, que apenas 'deposita' os conteúdos nos/as alunos/as. Defensor do saber popular e da conscientização para a participação, Paulo Freire inspirou muitos movimentos sociais que lutaram em busca da equidade social.

As premissas de Freire motivam até hoje ações da sociedade civil, de educadores/as e pesquisadores/as do Brasil e do mundo em prol da efetivação da cidadania, de uma educação emancipatória por meio das práticas educativas escolares e não escolares da Educação de Jovens e Adultos.

Ao desenvolver reflexões que tenham como foco a Educação de Jovens e Adultos com base no referencial freiriano, integram o presente Dossiê 12 textos oriundos de pesquisas e de experiências educativas em espaços escolares e não escolares. É evidente o fato de que ainda hoje a academia brasileira busca na obra de Paulo Freire formas de garantir melhorias à educação pública ofertada no país, valendo-se sempre de suas inestimáveis contribuições ao desenvolvimento de práticas educacionais voltadas a uma sociedade mais justa e igualitária.

O tex to Dialogicidade e humanização: algumas relações entre o diálogo e o modo de ser propriamente humano, de autoria de João Henrique Souza Santos, abre o dossiê. Por meio dele, assinala que quando se investiga o processo de humanização se constata que a dialogicidade é um elemento central nas obras de Paulo Freire, uma vez que expressa uma

\footnotetext{
${ }^{4}$ Os estudos sobre a obra de Paulo Freire trazem duas formas de adjetivar seus pressupostos. Alguns especialistas em Paulo Freire utilizam o "freireano", outros o "freiriano". Há justificativa para as duas terminações. Na apresentação, optamos por utilizar freiriano. Romão (2008) nos ajuda a justificar nossa escolha quando explica que os radicais e os afixos são base de significação e, por isso, não podem se alterar. Quando o sufixo "iano" é aposto a nomes próprios que terminam com a vogal "e", por uma questão de eufonia, na Língua Portuguesa, devem desaparecer. Assim, em coerência com esse pensamento, todas as vezes que nos referirmos ao legado de Paulo Freire, nesta apresentação, será utilizada a expressão freiriano ou freiriana e não freireano ou freireana. No entanto, preservamos nos artigos o uso de freireano ou freireana pelos/as autores/as que optaram por esse formato.
} 
dimensão fundamental ontologicamente constitutiva do ser propriamente humano. Segundo o autor, o diálogo se mostra nas reflexões de Paulo Freire como um fator central em qualquer processo pedagógico que pretenda humanizar, libertar e restituir a humanidade roubada dos oprimidos porque é uma exigência existencial, parte da vocação ontológica humana ao ser mais.

Em A potência do diálogo na constituição das identidades e resistências, Andrea Barros Daltro de Castro Costa e Antônio Marlon Matos Rios sugerem reflexão ampla acerca da expressão diálogo de forma a compreender a relação do uso deste termo com a constituição das identidades no contexto da Educação de Jovens e Adultos. Estruturam o texto a partir do mergulho teórico dos escritos de Paulo Freire sobre diálogo enquanto direito à palavra e dos estudos de Bakhtin e Bourdieu que incitam pensar o dialogismo enquanto constituição do ser. Esta discussão é relevante diante dos silenciamentos políticos e até mesmo fatais que urgem a construção de uma resistência que se faz e se refaz por meio da linguagem que se opõe à verticalidade monopolizadora do uso da palavra e preconceitos homogeneizadores, invalizadores e excludentes das diversidades das identidades construídas e modificadas ao longo dos tempos.

Na sequência, o artigo A educação em vias de libertação: uma análise filosófica da EJA em contexto de um Brasil (pro)fundo, de Rayane Ancelmo Leal, apresenta uma reflexão sobre a Educação para Jovens e Adultos, bem como a formação docente no contexto latinoamericano. Busca também analisar e, por isso mesmo, resgatar o contexto histórico, cultural e social da América Latina através de uma análise filosófica em vias de libertação. Tal proposta se justifica pela importância de uma educação latino-americana contextualizada, popular e democrática que contribua para a formação de identidade dos sujeitos, bem como sua autoestima como educandos. Esta investigação se apresenta como um farol em tempos sombrios, re-pensando e re-construindo o contexto educativo a partir das perspectivas pedagógica e filosófica de Enrique Dussel e Paulo Freire com ênfase nas categorias: Utopia e Amorosidade.

Em Dialogicidade e afetividade como princípios para uma educação libertadora na EJA, Marcos Vinicius Reis Fernandes, Glaucio Martins da Silva Bandeira e Marcia Soares de Alvarenga analisam a partir de estudos bibliográficos de obras de Paulo Freire as categorias dialogicidade e afetividade como aspectos necessários ao processo pedagógico na modalidade de Educação de Jovens e Adultos. Nesse contexto, compreendem que estas categorias estão diretamente relacionadas a um processo de ensino-aprendizagem voltado para emancipação 
humana dos estudantes trabalhadores. Desse modo, reconhecem que uma educação libertadora para a autolibertação destes sujeitos deve ser pautada na valorização de saberes intra e extraescolares que permeiam nas relações dialógicas e afetivas.

Já em A pedagogia freireana na educação não escolar: o teatro do oprimido em evidencia, Jocilene Oliveira Santos Brito e Nilma Margarida de Castro Crusoé analisam experiências formativas nas práticas educativas não escolares do Teatro do Oprimido a partir das narrativas de integrantes de um grupo de teatro do interior da Bahia. As autoras apresentam contribuições do pensamento freiriano para se pensar a educação não escolar, especificamente as ações desenvolvidas no Teatro do Oprimido, por imprimir formações voltadas para dimensões educacional, social e política ou, em outros termos, para uma educação política e social emancipadora.

$\mathrm{O}$ artigo "Não deixe morrer minha esperança": a experiência do MEBIC e as contribuições de Paulo Freire para a educação popular, de autoria de Adenilson Souza Cunha Júnior; Sônia Maria Alves de Oliveira Reis e Tatyanne Gomes Marques, narra um pouco a história do Movimento de Educação de Base de Iniciativa Católica (MEBIC), identificando o contexto sócio-político, abordagens teóricas e práticas pedagógicas. Conta que o projeto parte do pressuposto: “Alfabetizar é conscientizar-se, é aprender a escrever a vida, como autor e como testemunha da história, é biografar-se, é existenciar-se, é historicizar-se" (FREIRE, 1987, p. 10), e concebe a alfabetização não apenas como a aquisição do domínio da leitura e da escrita, mas como o desenvolvimento da capacidade de usar essas habilidades no âmbito pessoal e coletivo. As autoras e o autor do texto apresentam algumas narrativas dos/as educandos/as do MEBIC que revelam o desejo e a esperança de encontrar escolas que sejam acolhedoras e cuja organização do trabalho pedagógico seja acessível a eles, que satisfaçam as demandas de aprendizagem do/a trabalhador/a.

Já o artigo Memória das reitoras sobre gestão democrática universitária: perspectivas freirianas, de Josias Benevides da Silva, analisa a memória coletiva de reitoras, no que se refere à gestão democrática e participativa, à luz da teoria de Paulo Freire e outros autores que discutem temáticas relacionadas ao poder e gestão democrática da educação. $\mathrm{O}$ autor revela que, da mesma forma que Paulo Freire entende processos democráticos e participativos, as mulheres que foram reitoras no Estado da Bahia percebem que não se pode falar em democracia e participação sem a inclusão do gênero feminino nas relações de poder.

Para dar prosseguimento à composição do dossiê, apresentaremos dois textos que conferem foco à elaboração freiriana no que concerne à Educação de Jovens e Adultos em 
privação de liberdade. De autoria de Tailan Cristina Maciel e Vanessa Elisabete Raue Rodrigues, o texto A pedagogia freireana e a EJA na educação dos sujeitos privados de liberdade: possibilidades e entraves busca, por meio de uma investigação bibliográfica, as influências e as contribuições da pedagogia de Paulo Freire na Educação de Jovens e Adultos daqueles que estão privados de liberdade. As autoras apontam a educação a partir da pedagogia freiriana, como um meio de reinserção social, promoção da autonomia, emancipação e reinserção social do sujeito aprisionado. Procuram ainda, contemplar a educação nas prisões como uma prática para a liberdade, para além das grades, para a vida e convivência em sociedade. Da mesma forma, Educação de Jovens e Adultos em privação de liberdade: reflexões a partir da pedagogia da autonomia de Paulo Freire, artigo de Leticia Povala Li, Reinaldo Rodrigues Monção Junior e Vitória Cristina da Silva Coutinho, relata uma experiência de estágio realizado na Educação de Jovens e Adultos (EJA) em privação de liberdade na região metropolitana de São Paulo. As autoras e o autor provocam reflexões sobre a prática docente a partir da obra Pedagogia da Autonomia: Saberes Necessários à Prática Educativa (FREIRE, 1997). O estudo revela a construção de saberes como prática potencialmente libertadora em contexto de privação de liberdade e faz um chamado à esperança como prática pedagógica, sem ignorar os desafios forjados nas estruturas e agravados pela pandemia da Covid-19.

Em $O$ ensino de Geografia e história na Educação de Jovens e Adultos: um relato de experiência em Araraquara, Letícia Negrão Chamma, Jonathan Lambert Silva, Vinícius Azevedo e Gabriel Augusto Vilela apresentam o ensino de História e Geografia em uma unidade escolar de Educação de Jovens e Adultos no município de Araraquara, interior do Estado de São Paulo. Assim, como no texto anterior, as observações relatadas nesse texto são fruto do estágio da licenciatura em Ciências Sociais realizado no segundo semestre de 2019. Após contextualização do ambiente escolar, a autora e os autores discutem algumas das particularidades observadas nas aulas das referidas disciplinas, bem como seu conteúdo e a didática. Notaram que aspectos da educação "bancária" (FREIRE, 1987) e da falta de autonomia e planejamento das aulas se fazem presentes nas práticas de ensino presenciadas.

Os dois últimos textos do dossiê se debruçam sobre o referencial teórico freiriano para a compreensão do novo cenário da EJA, marcado pela atual pandemia Covid-19. De autoria de Gilvan dos Santos Souza, Jaciara de Oliveira Sant'Anna Santos e Adenilson Souza Cunha Júnior, o artigo Narrativas de estudantes da EJA no contexto da pandemia da Covid-19: reflexões a partir do olhar freireano discute, por meio da análise de narrativas de estudantes 
da EJA, o papel do professor no processo de amorosidade e acolhimento desses sujeitos, durante o período de pandemia e o fechamento das unidades escolares. Acreditam que o aspecto da amorosidade é de fundamental importância no contexto atual para a permanência desses sujeitos na escola. As narrativas dos/das estudantes da EJA revelaram a necessidade de a sala de aula ser um espaço humanizador de diálogo e escuta, propiciando acolhimento. Fechando o dossiê, temos a contribuição de Helga Valéria de Lima Souza e Carlos Alberto Lopes de Sousa, com o texto intitulado Situação-limite e inédito-viável: percepções e ações de professores e professoras da EJA no sistema on-line. Nele, o autor e a autora indicam as motivações geradoras e o desenvolvimento de uma pesquisa em nível de doutorado, e ainda em fase de conclusão, que teve como sujeitos os/as professores/as atuantes na modalidade Educação de Jovens e Adultos, via sistema on-line, antes e durante a pandemia da Covid-19. Entre os objetivos atendidos, destacam-se a busca pelas percepções e ações correspondentes aos conceitos de situação-limite e inédito-viável (FREIRE, 2001; 2018).

Essa riqueza de temas discutidos nos 12 textos desse dossiê instiga-nos a mergulhar no trabalho de diferentes pesquisadores e pesquisadoras para participar do universo de leituras realizadas sobre Freire e a EJA, em um momento histórico profícuo para a divulgação de seu pensamento e de sua práxis libertadora, autêntica, revolucionária, de natureza humanizadora, ética, estética, crítica e amorosa.

As 12 publicações que estão neste dossiê contribuem para a constatação da atualidade de Paulo Freire como um pensador do século XXI. Motiva-nos a compreender a urgência que temos sobre a necessidade do diálogo, do amor a toda forma de vida, com a devida reflexão sobre o que é a existência humana, sobre o que significa nossa atuação neste mundo por meio da educação como ato político, que nos guie rumo a desenvolver, efetivar e constituir a verdadeira "humanidade".

O dossiê expressa o nosso compromisso com propagação do legado de Paulo Freire, em um momento histórico difícil, atravessado por diversas formas de opressão, pelo conservadorismo e pelo autoritarismo que nos cobram a busca de esperança e o fortalecimento coletivo para traçar novos caminhos educativos! Em Freire, encontramos a possibilidade de ler a palavra e reler o mundo que antes líamos, pensarmos esse mundo na direção de uma vida digna para todas as pessoas! Paulo Freire vive!

Agradecemos a todos/as autores/as, avaliadores/as e apoiadores/as deste dossiê sobre Paulo Freire e a Educação de Jovens e Adultos. Desejamos a todas as leitoras e a todos os leitores um excelente estudo dessas importantes produções! Abraços fraternos!

Revista Educação e Ciências Sociais, Salvador, v.4, n.7, 2021. 


\section{REFERÊNCIAS}

FREIRE, Paulo. Pedagogia do oprimido. 17. ed. Rio de Janeiro: Paz e Terra, 1987.

FREIRE, Paulo. A importância do ato de ler: em três que se completam. 23. ed. São Paulo: Cortez: Autores Associados, 1989. (Coleção Polêmicas do Nosso Tempo, v. 4).

FREIRE, Paulo. Pedagogia da autonomia: saberes necessários à prática educativa. Rio de Janeiro: São Paulo: Paz e Terra, 1997.

FREIRE, Paulo. Pedagogia dos sonhos possíveis. Organização de Ana Maria Araújo Freire. São Paulo: Editora UNESP, 2001.

FREIRE, Paulo. Pedagogia do Oprimido: (o manuscrito). Paulo Freire; Jason Ferreira Mafra; José Eustáquio Romão; Moacir Gadotti (projeto editorial, organização, revisão e textos introdutórios). São Paulo: Editora e Livraria Instituto Paulo Freire; Universidade Nove de Julho (UNINOVE): Big Time Editora / BT Acadêmica, 2018.

GADOTTI, Moacir. Prólogo: el proyecto utópico de Freire. In. LENS, José Luís. Paulo Freire: su práxis pedagógica como sistema. Buenos Aires, Argentina: Yagüe Ediciones, 2001.

ROMÃO, José Eustáquio. Pedagogias de Paulo Freire. Revista Múltiplas Leituras, v.1, n. 2, p. 8-22, jul. / dez. 2008. Disponível em: https://www.metodista.br/revistas/revistasims/index.php/ML/article/viewFile/1540/1574. Acesso em: 15 set. 2021 